\title{
Analysis of Health Workers' Perceptions on Medical Waste Management in Tanzanian Hospitals
}

\author{
Ignasio S. Kagonji, Samwel V. Manyele* \\ Department of Chemical and Mining Engineering, University of Dar es Salaam, Dar es Salaam, Tanzania \\ Email: kagonji@yahoo.com, 'smanyele@udsm.ac.tz
}

Received 31 March 2016; accepted 22 July 2016; published 25 July 2016

Copyright (C) 2016 by authors and Scientific Research Publishing Inc.

This work is licensed under the Creative Commons Attribution International License (CC BY). http://creativecommons.org/licenses/by/4.0/

(c) (i) Open Access

\section{Abstract}

This paper presents the perceptions of health workers (HWs) on medical waste management (MWM) issues in Tanzanian hospitals. The perceived total waste generation rates were lower than the actual measurements. Administrators perceived lower rates than implementers. The results indicated three categories of medical waste which are given due attention, that is, sharps waste, pathological and infectious waste. Other wastes like radioactive, chemical, pharmaceutical, pressurized containers receive very little attention. Container colour coding and labelling was negligible, while improvised containers are still in use. Medical waste is transported within hospitals manually, with little efforts on mechanized transportation. Poor waste storage was observed, while the prominent medical waste treatment technologies are medium temperature incinerators. Off-site transportation of medical waste is practiced, where the waste is finally dumped or buried. The hospitals are currently utilizing public-private partnership schemes for MWM in only one aspect of off-site transportation. Three main problems which require high attention include: Weaknesses in hospital management, poor MWM infrastructure, and lack of skills and knowledge on MWM among HWs. Knowledge and awareness among HWs on health hazards associated with poor MWM is low (with exception of cholera, HIV and typhoid). Few PPE types are supplied and used in the hospitals, leading to poor diseases prevention. There is also low knowledge among HWs on administrative issues related to MWM in Tanzanian hospitals.

\section{Keywords}

Medical Waste Management, Health Workers' Perceptions, Waste Generation, Waste Segregation, Waste Transportation, Waste Treatment and Disposal

\footnotetext{
${ }^{*}$ Corresponding author.
} 


\section{Introduction}

The different views and perceptions observed in medical waste generation, segregation, collection, transportation and storage, treatment and disposal, between administrators and implementers affects MWM especially in the area of planning and resource allocation within health facilities. In this study, much effort has been put into identifying how HWs understand and cope with the problems of MWM [1]-[3].

The analysis of HWs' perception on medical waste segregation included practices of HWs on medical waste segregation by category of waste, where segregation is taking place in hospitals, type of containers used, and containers' colour coding and labelling. Container colour coding and labelling is a very important aspect of medical waste segregation and also injection safety, which depends strongly on the HWs' perceptions. Colour coding and labelling helps HWs to locate containers they need for a specific type of waste. Moreover, waste handlers can put more attention on containers intended to contain sharps waste and minimize accidents. Improper handling of medical waste can bring occupational hazards. The infectious waste produced in the course of healthcare activities carries a higher potential for infection and injury.

The organization of collection and on-site transportation activities depends on the type of medical waste, human resources, infrastructure and equipment availability. At least two collections per day is a normal schedule (one in the morning and one in the afternoon), and whenever it would be necessary. Medical waste collection, storage and transportation are three inter-dependent processes. Medical waste collection is done inside hospital sections and departments. To make the process of collection possible, waste storage facilities need to be kept in place. To remove medical waste collected at the generation point to the collection centre, transportation facilities are important. The popular containers used for medical waste collection in Tanzanian hospitals are plastic bags, safety boxes and plastic bins [4] [5].

All medical waste management processes require proper planning and implementation by HWs of all levels [6]. Segregation of the medical waste by categories also depends on what HWs perceive on the risks posed by the waste categories [7]. Awareness among HWs on the diseases that can be transmitted through handling medical waste is a critical factor in minimizing infection transmission. To minimize risks, provision of medical waste handling infrastructure (which depend strongly on skills and commitment among hospital management team members), is of great importance.

Training HWs in implementing the MWM programme is critical [8] [9]. The training should aim at developing awareness on health, safety, and environmental issues relating to medical waste, and how these can affect the community and employees. Such training should highlight the roles and responsibilities of HWs in the overall management programme, especially the waste handlers. In this study, training needs for HWs were established. Assessing the working conditions for all HWs regarding MWM brings a challenge on their safety and performance (although not part of this study). Treatment of medical waste calls for technical skills and financial resource allocation, while the availability and use of PPE in hospitals forms a large part of HWs' perceptions and which require critical analysis [10]-[12].

The study was motivated by concerns that the development and adoption of MWM systems in hospitals are being hampered by wrong perceptions among different HWs' categories. Relatively few studies have been conducted to address HWs' views on MWM issues.

\section{Literature Review}

The quantities of medical waste generated, among other factors, depend on the level and activities of the hospital (general medical treatment, clinical investigation, wards activities, etc.), level of instrumentation (operations, labour, etc.) and sometimes location of the facility, i.e., rural or urban settings [4] [13]-[16]. Studies have been done on medical waste generation in Dar es Salaam, Tanzania [13]. The medical waste generation rates in the surveyed hospitals were obtained by actual measurements and through assessment of the storage facilities emptying frequencies and degree of filling of the waste receptacles [4]. The hospitals with better medical facilities were reported have higher waste generation rates [6] [15]. Moreover, the average waste generation rate is estimated to be $0.66 \mathrm{~kg} /$ patient/day with a range of $0.03-2.0 \mathrm{~kg} /$ patient/day [13] [17]. Comparing hospitals in rural and urban settings in Tanzania, generation rates of 1.8 and $2.0 \mathrm{~kg} /$ patient/day for Amana and Ligula hospitals, respectively, has been reported [16].

Among all the categories of medical waste produced in district and regional medical institutions, in which almost all the ranges of medical activities are practiced, the following categories dominate: non-risk medical 
waste or domestic waste, pathological, infectious, sharps, pharmaceutical, chemical and special hazardous waste such as radioactive and cytotoxic waste [4].

The safe and cost effective way to manage medical waste disposal is through segregation into infectious and non-infectious categories. In this way, the general waste can be disposed of cost-effectively through normal channels and taken to landfill and infectious waste can be treated safely before final disposal [18]. This reduces the risks of infections and control of the costs involved in treatment [5] [19]. Segregation should always be the responsibility of the waste generator, and should take place at the point of generation, maintained in special colour-coded and labelled containers with tight fitted lids [20].

Inadequate knowledge of handling of healthcare waste can have serious health consequences and a significant impact on the environment as reported in literature [3] [8] [9] [17] [21]-[23]. Handling medical waste require use of PPE such as heavy gloves to prevent cuts, pricks and heat, recommended masks to control dust, smoke and powdered chemicals. Low knowledge among HWs on the risks associated, burning medical waste in open air especially plastic and packaging materials, burying medical waste without prior-treatment [19], pose threat not only to the employees working in the hospital but also to the community around that area. Diseases like hepatitis B and C, HIV, typhoid, cholera, etc., are likely to be transmitted through medical waste [24].

A storage location for medical wastes should be designated inside the health facility. The waste in bags or containers should be stored in a separated area, room, or building of a size appropriate to the quantities of medical waste generated. The storage should be easily accessible by staff handling waste, inaccessible to animals, insects and birds, protected from the sun, not near to food store and food preparation areas [5] [18].

Nursing-assistants allocated in those areas are required to transport and drop off the waste to the storage or disposal points [19]. In some facilities medical waste is not collected on a regular basis and transported to a central storage area leading to accumulation of medical waste in wards and other working rooms [18]. The collection should follow specific routes to reduce the passage of loaded carts through wards and other clean areas. Most of the carts are not easy to load and unload, have sharp edges that damage medical waste bags and containers and are not easy to clean [19].

The appropriate treatment technology should be applied for the relevant medical waste; this refers to the application of technology that is reliable, affordable and sustainable in accordance with the existing regulations bylaws and, technical, human and financial resources available. The methods in place are autoclave, chemical treatment, liming, encapsulation and incineration. The health facility administrators are advised to choose the technology that minimizes public health risks associated, and achieve the lowest impact on the environment. Disposal methods vary according to type of waste, local environment, available technology, acceptance and costs. However, the most appropriate, cost-effective and efficient method used in Tanzania is incineration. The incinerator design recommended by WHO in 2006 was the dual chambered "De Montfort incinerator" [19], which, however, has many pitfalls, leading to new and successful developments in the incineration technology in Tanzania.

The prevalence of infectious and occurrence of infections associated with medical waste among the HWs and in the nearby society, calls for interventions in health education and promotion [19]. HWs and waste handlers are the most critical element in the management of medical waste. It is envisaged that a well-trained and deployed personnel will adequately cope with health and environmental risks [7] [8]. However, at healthcare facility level, there are no purposeful programs for training and awareness on MWM [1] [2] [9] [25].

The minimal training for MWM operators should include: information on the risks associated with the handling of medical waste, procedures for dealing with spillages and other accidents and instructions on the use of protective gears [3] [7] [8]. The training needs will depend on the type of operations and the technology involved, but may include special topics such as operation of incinerators and waste transportation. Information levels of all healthcare managers who had received training on waste management are normally raised at the completion of that training session [3] [9]. The lack of proper and complete knowledge about MWM impacts practices of appropriate waste disposal [8].

Promotion of the appropriate handling and disposal of medical waste is important for public health. Every member of the community should have the right to be informed about potential health hazards. The objectives of public education on medical waste include: prevention of exposure to medical waste and related health hazards which might be voluntary in the case of scavengers or accidental as a consequence of unsafe disposal methods, creation of awareness and foster responsibility among patient and visitors in hospitals regarding hygiene and MWM, informing the public about risks linked to medical waste focusing on people living or working in close 
proximity to/or visiting healthcare establishments, family of patients treated at home, and scavengers on waste in dumps [1] [2].

\section{Methodology}

\subsection{Study Areas}

This study was conducted in two Tanzanian hospitals (Amana hospital in Dar es Salaam city and Ligula hospital in Mtwara) to have different views of urban and rural hospital settings. Amana and Ligula hospitals were chosen as study areas in order to have comparison between hospitals in large and crowded cities and that of up countries with moderate interactions. Also these hospitals are Government facilities fully registered with all departments and services needed. The number of beds was 290 and 360 while the daily inpatients were 400 and 500 for Amana and Ligula hospital, respectively. The bed occupancy rate was the same for both hospitals, that is, 1.4 patients/bed/day. The daily outpatients were 860 and 720 per day with 296 and 223 staff for Amana and Ligula hospitals, respectively. Moreover, both hospitals are publicly owned.

\subsection{Target Population and Group Characteristics}

A total of 210 respondents were planned to be involved in the study, whereby, 105 were from Amana (35.5\% of total staff) and the other 105 were from Ligula hospital (45.1\% of total staff). Out of these, 206 (98\%) responded and 4 (2\%) were unable to participate due to various reasons. In Amana hospital, out of 105 people who were included in the sample 104 (99\%) responded and only 1 (1\%) did not respond, whereby 57\% were female and $43 \%$ male, with their age ranging from 22 to 54 years (mean age 38). At Ligula hospital, on the other hand, out of 105 respondents included in the sample 102 (97\%) participated in the study and 3 (3\%) did not participate, where by 62\% were female and 38\% male, with their age ranging from 21 to 59 years (mean age 40). The selected staff per category was: 7 administrators, 40 nurses, 8 paramedical staff and 40 waste handlers from each hospital. The number of doctors was 9 from Amana and 7 from Ligula hospital.

\subsection{Data Collection Methods}

Secondary data were collected from various documentary sources such as facility quarterly and annual reports, health management information system, evaluation reports, supervision reports and from different studies associated with MWM practices including technology performance. Primary data were collected via structured questionnaire with both open and close ended questions.

This study has organised information and statistics on MWM practices in hospitals from generation to final disposal. The perceptions of HWs on MWM have been properly analysed to give information that forms the basis for realistic planning, budgeting and implementation of MWM in economical, effective and efficient way. The study covered workers' perceptions in the following issues: medical waste generation; medical waste segregation; segregation practices, areas where medical waste segregation takes place; types of containers used for medical waste segregation and container colouring and labelling; medical waste collection, storage and transportation; impact of medical waste disposal technology on the environment; problems facing MWM in hospitals; awareness of diseases associated with poor MWM; knowledge and skills of HWs on MWM, training need assessment, PPE availability/utilisation, and knowledge of HWs on administrative issues.

\section{Results}

\subsection{Medical Waste Generation Rate}

HWs in both hospitals were probed on their perceptions on medical waste generation rate in relation to each category of medical waste. The waste categories studied were: general waste, pathological, radioactive, chemical, infectious, sharps, pharmaceutical and pressurized containers, as summarized in Figure 1. Taking an example of only two categories; Amana hospital general waste generation was perceived by waste handlers to be $240 \mathrm{~kg} / \mathrm{day}$ almost corresponding to nurses (200 kg/day) while doctors perceived an average generation rate of $30 \mathrm{~kg} / \mathrm{day}$ and supervisors $80 \mathrm{~kg} /$ day. Infectious waste was perceived by waste handlers and nurses to be over $250 \mathrm{~kg} / \mathrm{day}$ while doctors perceived it to be $40 \mathrm{~kg} /$ day and supervisors rated it at $90 \mathrm{~kg} / \mathrm{day}$. In a similar fashion, at Ligula hospital the general waste generation rate was perceived by waste handlers to be over $200 \mathrm{~kg} / \mathrm{day}$ and nurses 


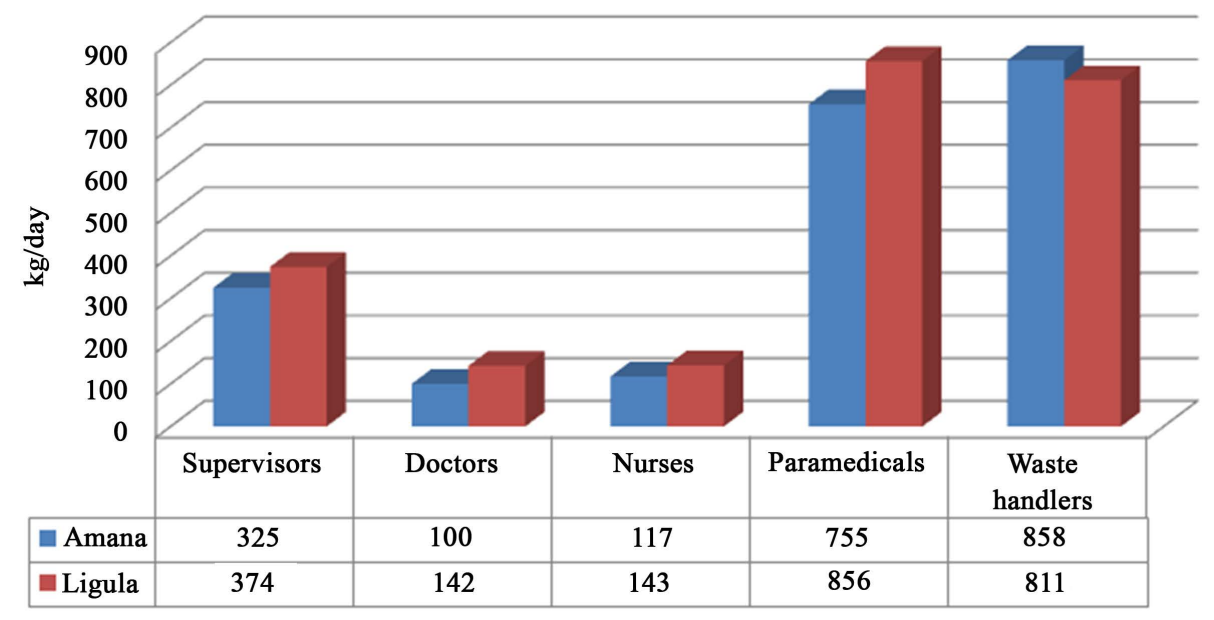

Figure 1. Health workers’ perceptions on daily medical waste generation rates for Amana and Ligula hospital.

above $250 \mathrm{~kg} /$ day while doctors preserved it to be only $50 \mathrm{~kg} /$ day and supervisors almost $100 \mathrm{~kg} /$ day. Infectious waste was perceived by waste handlers to be $240 \mathrm{~kg} /$ day and nurses to be over $250 \mathrm{~kg} /$ day while doctors perceived it to be about $50 \mathrm{~kg} /$ day and supervisors $100 \mathrm{~kg} /$ day. Thus, a remarkable difference exists among HWs' perceptions in both hospitals.

Perceptions on the total medical waste generation in those hospitals were also studied among different health worker carders. The results when integrated revealed that, even waste handlers and nurses who are the majority in both hospitals, viewed the generation rate to range from 800 to $1000 \mathrm{~kg} /$ day which are lower than the total average measured medical waste, from which Amana produces 2251 kg/day and Ligula 2484 kg/day [16]. The administrators (doctors and supervisors) who are the planners and decision makers in resource allocation viewed the generation rate to range from 100 to about $500 \mathrm{~kg} /$ day only.

\subsection{Medical Waste Segregation}

When assessing medical waste segregation practices, it was observed that over $60 \%$ of HWs at Ligula hospital segregate their waste in their sections and over 80\% do the same in Amana hospital. This indicates that HWs in both health facilities are aware of the importance of medical waste segregation (with stronger awareness at Amana hospital) than Ligula hospital.

Based on categories of waste, over $80 \%$ of sharps waste in Ligula hospital and 100\% in Amana hospital are being segregated and hygienically collected. The cause of such successes can be attributed to the fact that, special yellow sharps containers were being distributed for free by WHO as part of immunization campaign. Pathological waste was being segregated at 95\% and 82\%, while infectious waste was segregated at 96\% and 84\% efficiency in Amana and Ligula hospitals, respectively, as shown in Figure 2.

When three areas where segregation can take place (at source, at storage and at disposal point) were assessed, the result showed that in Amana hospital, about 75\% of all medical waste are being segregated at source, 15\% at storage area and $10 \%$ at the disposal point while in Ligula hospital, $65 \%$ of waste are being segregated at source, $20 \%$ at storage area and $15 \%$ at disposal point. In both hospitals, segregation at source was higher, which indicates that most of medical waste generators are only aware of the importance of segregation at source. Segregating waste at storage areas and scavenging at the disposal point is also practiced in both hospitals, the situation being worse at Ligula hospital.

\subsection{Medical Waste Collection, Transportation and Storage}

Types of containers used for medical waste segregation and collection were also assessed in the two hospitals. Five types of containers which are mostly used in Tanzanian hospitals were included in this assessment, that is, plastic bags, safety boxes, plastic bins, metal bins and improvised containers as summarized in Figure 3. Result showed that, in both hospitals safety boxes are highly used (above 90\%). This is because, the safety boxes were being supplied free of charge by WHO during immunisation campaign. Plastic bins are highly utilised by 


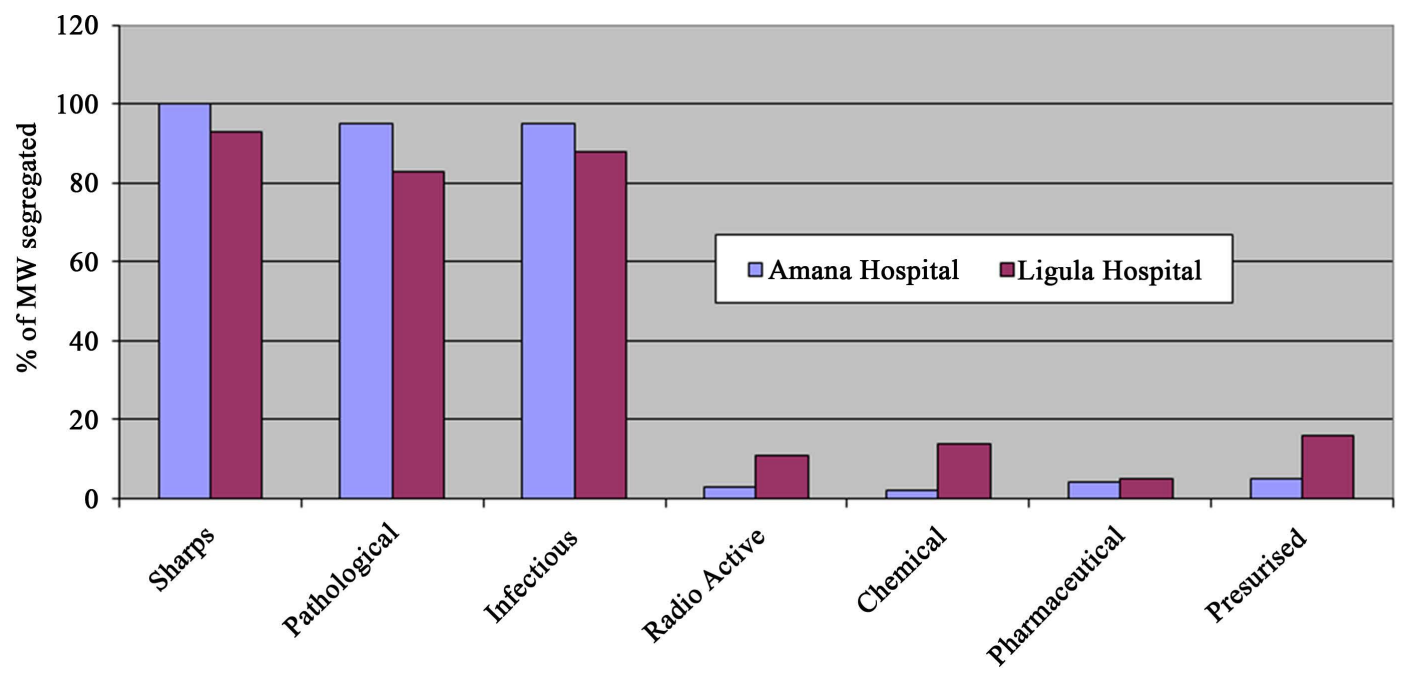

Figure 2. Efficiency of segregation for different medical waste categories.

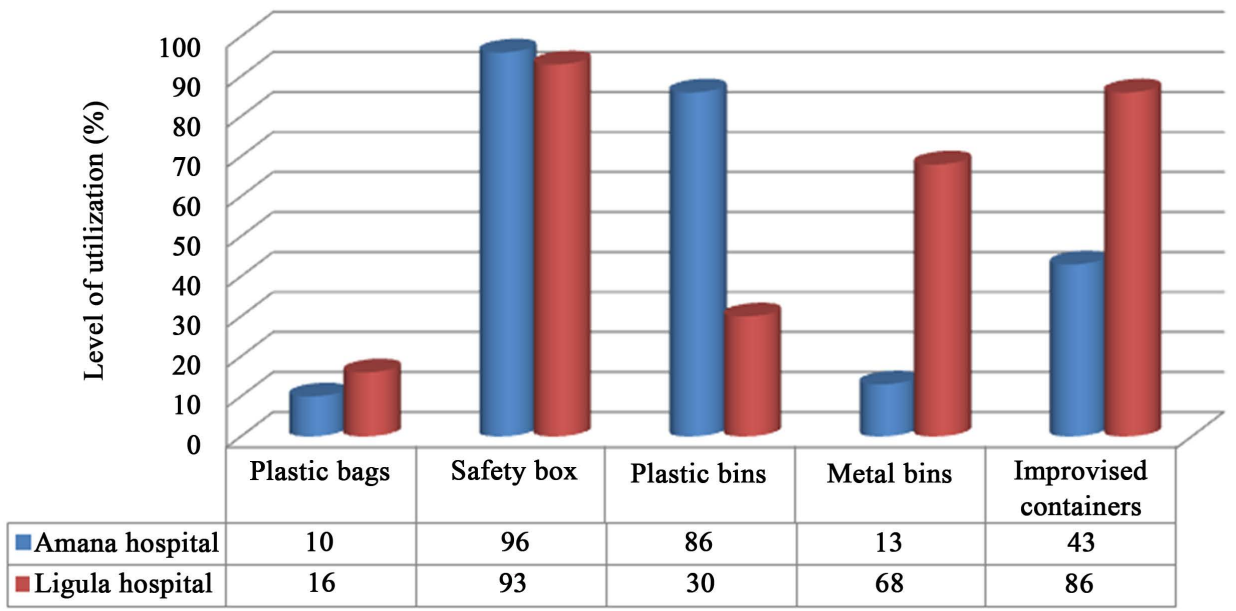

Figure 3. Containers used for medical waste collection.

Amana hospital (86\%) and less used (30\%) by Ligula hospital. On the other hand, metal bins are less utilised in Amana (13\%) and highly utilized in Ligula hospital (68\%) while improvised containers are highly utilised at Ligula hospital (86\%) than in Amana hospital (43\%).

Result showed that, the extent of container coding and labelling is almost negligible as its implementation was observed to be very low. In Amana and Ligula hospitals, only $20 \%$ and $14 \%$ of the containers were colour coded and labelled, respectively. After medical waste collection and storage, waste must be removed from the point of generation and transported to the waste storage centre at a specified frequency. The collection frequency depends on size of the containers used, waste generation rate and types of waste generated, which again hampered by other factors including staff availability. In both hospitals, most of medical waste was collected daily. At Amana hospital, about $85 \%$ of medical waste was collected daily, while the daily collection for Ligula hospital was only $75 \%$ of the waste. In both hospitals, less than $10 \%$ of medical waste was collected twice a day, while less than $5 \%$ was collected weekly.

\subsection{Onsite Transportation and Storage of Medical Waste}

Medical waste transportation facilities inside hospitals were also studied in line with frequency of collection from generation points to storage bays. Wheelbarrows are used when the waste has already been removed from the generation point, whereby, two to three bins are loaded on a trolley and transported to the collection centre. 
Some hospital sections do not have wheelbarrows at all and waste is transported by hands from generating point to the waste collection centre.

In Amana hospital, $40 \%$ of medical waste (bins and bags) is transported by hands, compared to Ligula hospital, where waste transported by hands amounts to $33 \%$. Lack of wheelbarrows for medical waste transportation was observed in both hospitals, whereby, only $16 \%$ and $10 \%$ of the total waste is transported using wheelbarrows in Amana and Ligula hospitals, respectively. There were no carts designated solely for the purpose of transporting medical waste in any of the hospitals, which lowers waste transportation efficiency and creates nuisance and unhygienic working conditions, as shown in Figure 4.

A survey of waste storage facilities at Amana hospital indicated that, 38\% of all pathological and infectious wastes collected are stored in a special sealed room provided near the theatre, while other waste is stored at the waste collection bay (40\%), as shown in Figure 4. The waste storage zone is not built to the acceptable standards although it is well kept and screened to avoid scavenging. At Ligula hospital, on the other hand, about $75 \%$ of the waste collected is stored in the waste collection bay which is, however, not well kept and maintained while the other waste (20\%) remain uncollected, heaped on open ground near the hospital departments. The only waste which is well managed is the waste from theatre rooms (5\%) which is kept in sluice room.

\subsection{Outsourcing of Medical Waste Collection and Transportation Services}

Outsourcing of medical waste management services in the health facilities was among the aspects studied. At Amana hospital, $47 \%$ of waste is managed by a private company, which uses municipal vehicles to transport
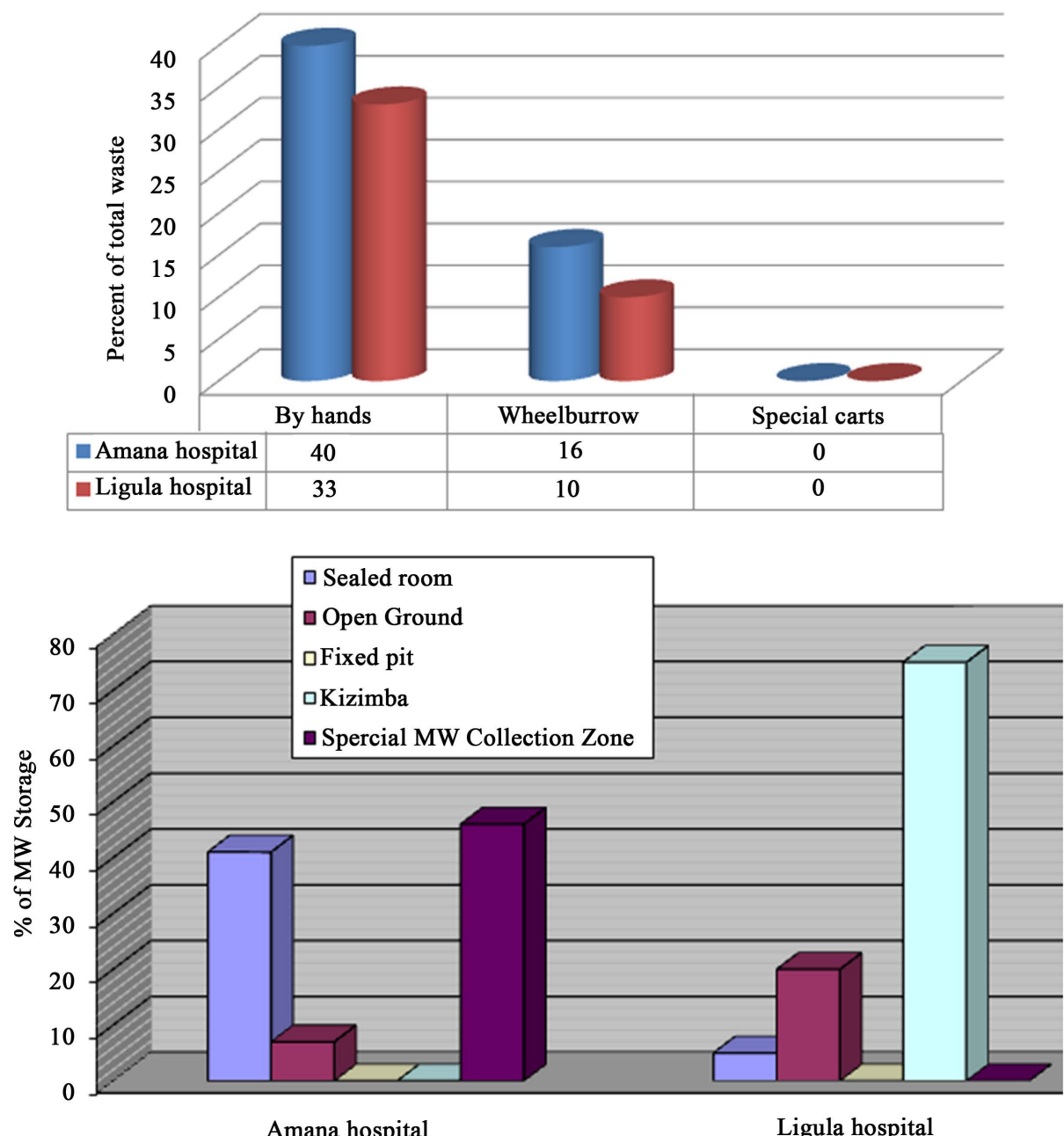

Figure 4. Onsite transportation equipment and storage facilities used. 
waste that cannot be handled by the onsite incinerator and treated waste residuals amounting to $45 \%$ of the waste generated. At Ligula hospital, on the other hand, medical waste is handled by the hospital and only a small amount (4\%) is collected by municipal vehicles on special request. The collection from wards and hospital sections to the collection centre is internally done by nurses and nurse auxiliary.

\subsection{Medical Waste Disposal Methods}

The onsite disposal methods assessed include: open burning on the ground, open burning in a pit, high temperature incineration, medium temperature incineration, low temperature incineration, burial, crude dumping and transportation to off-site, as summarised in Figure 5. When the HWs perceptions on utilisation of disposal technologies were analysed, it was observed that open burning on the ground is not practiced in both hospitals. Open burning in a hole is practiced (Amana 8\% and Ligula 19\%) and is mainly used to burn papers and packaging materials. High temperature and low temperature incinerators are not used in these facilities, while the medium temperature incinerators were the main onsite treatment method utilised with the temperatures ranging from $500^{\circ} \mathrm{C}$ to $600^{\circ} \mathrm{C}$ for Amana and $400^{\circ} \mathrm{C}$ to $500^{\circ} \mathrm{C}$ for Ligula. The irritating smell and smoke coming out of those incinerators was a concern in the surrounding communities. At Ligula hospital, the situation was much worse as the smoke was heavy, black and pungent. About 33\% of medical waste in Ligula hospital was being buried under the ground while the practice is not exercised at all in Amana hospital, as most of its waste (about 54\%) is transported off-site. The off-site transportation in Ligula hospital was observed to be 5\% only, as shown in Figure 5. Management of the medical waste transported off-site was also investigated. The result showed that sanitary land filling is not practiced at all, since only dumpsites are in use in Tanzania. The main offsite treatment method used to dispose medical waste was crude dumping together with burning and burying.

\subsection{Identification of Key MWM Problems in Hospitals}

According to HWs' perceptions, the problems leading to poor MWM in hospitals included: inappropriate onsite transportation facilities, inappropriate storage/collection facilities, inappropriate onsite treatment/disposal facilities, low skills and knowledge on MWM among HWs, limited PPE provision/utilisation, lack of SOPs in hospitals and lack of commitment among the hospital management team. The three major problems at Amana and Ligula hospitals were mainly weaknesses in hospital management, lack of MWM facilities and low skills and knowledge among HWs on MWM, as identified using Pareto principle (Figure 6). The other factors such as lack of PPE supplies and utilisation and poor treatment technologies were the least in magnitude, as summarised in Figure 6. That is, there is a close similarity between perceptions of HWs on MWM problems in both hospitals.

Moreover, a strong resemblance in the nature of problems was observed between the two hospitals. Thus, if the first three problems are solved using the limited resources, the hospitals will have solved $80 \%$ of the bottlenecks in MWM. The first and third problems involve changes in mind-sets which require training while number 2 involves financial resources to acquire physical infrastructure.

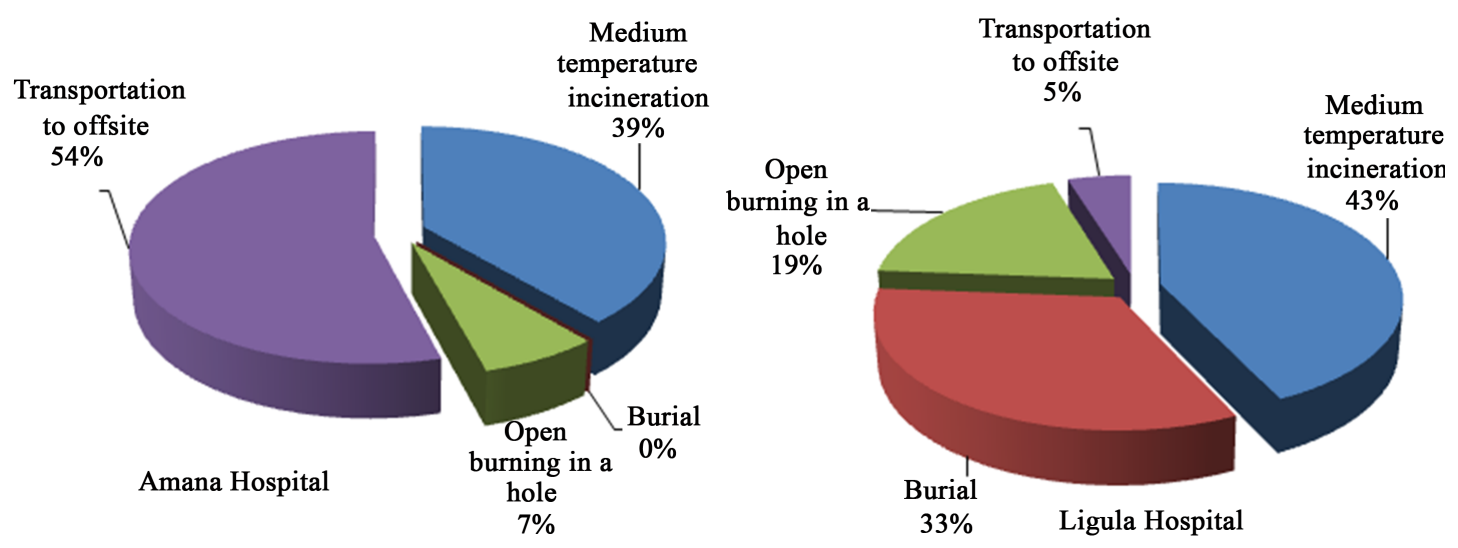

Figure 5. Onsite medical waste treatment methods practiced at Amana and Ligula hospitals. 

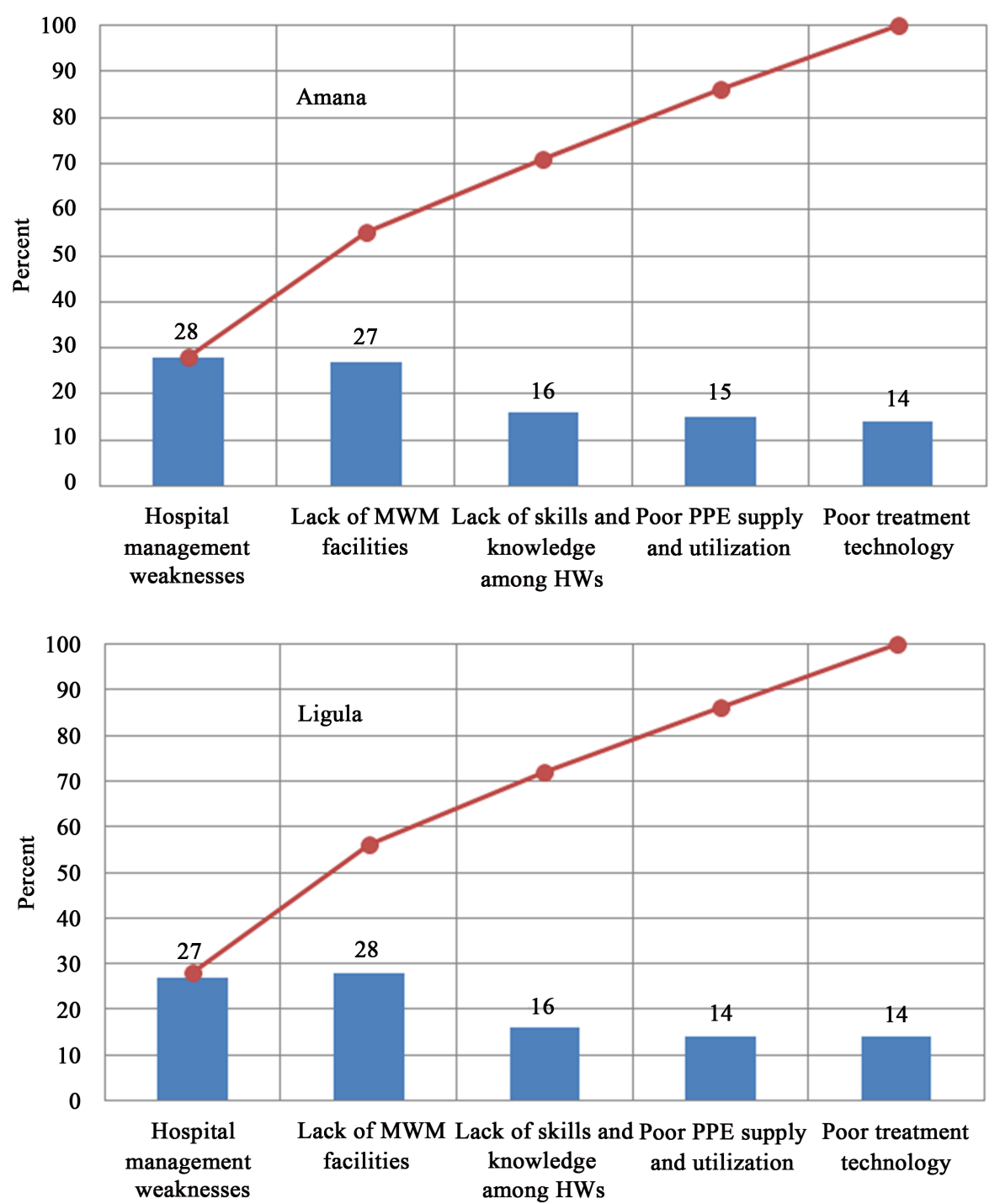

Figure 6. Comparison of MWM problems facing Amana and Ligula hospitals using Pareto charts.

However, when the results were compared between Amana and Ligula hospitals, it was revealed that though the hospitals are situated at different locations and of different settings, they are both experiencing similar problems. Based on Pareto analysis (Figure 6), the three problems which came out of this study as major bottlenecks hindering MWM in both hospitals and requiring high attention appeared to be: Weaknesses in the hospital management team (including lack of SOPs and commitment), lack of MWM facilities (inappropriate transportation equipment, collection and storage facilities). The third problem was low levels of knowledge and skills among HWs on MWM. The last two problems (inappropriate medical waste treatment/disposal technologies and poor PPE supply and utilization are minor problems which can be solved easily at a later stage. Thus, solving the first three (accounting for $80 \%$ of the problems) will solve most of the problems facing the hospitals.

\subsection{Diseases Awareness and PPE Utilization during MWM}

High awareness on diseases associated with MWM can assist in improving MWM. In both hospitals, the awareness of HWs on different types of diseases related to MWM was studied. It was revealed that the awareness level of HWs on cholera, HIV and hepatitis B is above $50 \%$ but for all other diseases it is about $50 \%$ and below as shown in Figure 7. This indicates that there is low awareness among HWs on the risk posed by different diseases associated with poor MWM. When a thorough analysis was done on how to overcome the problem of 


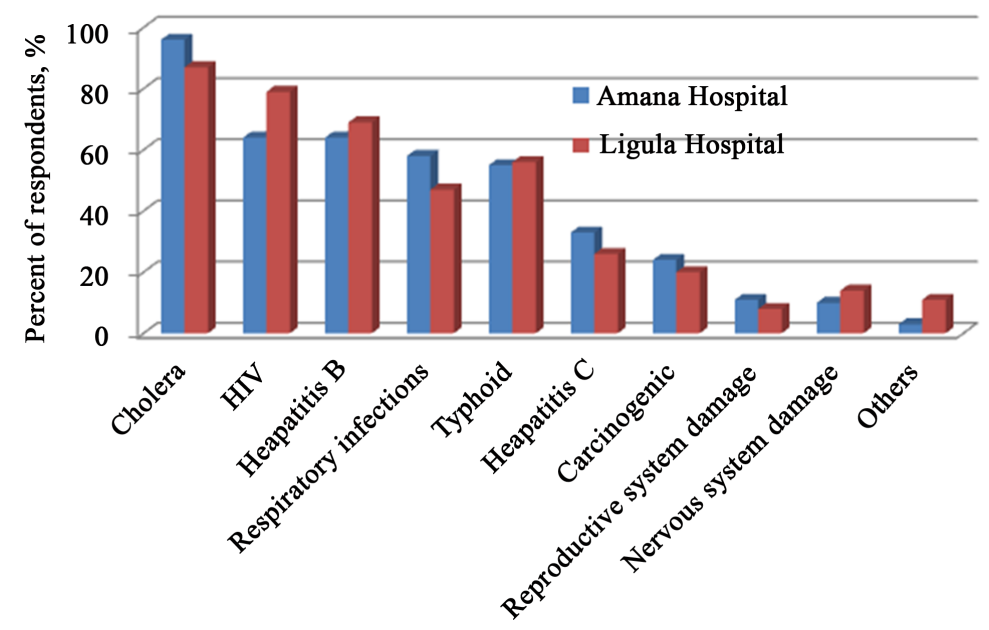

Figure 7. Level of disease awareness at Amana and Ligula hospitals.

HWs contracting these diseases, the PPE supply and utilization was a major issue as part of infection prevention program.

Based on the level of PPE supply, the results showed that, PPE available in hospitals include gloves (90\% in both hospitals), apron (65\% Amana/75\% Ligula) and masks (55\% Amana/58\% Ligula) while availability of all other types of PPE were ranked below $50 \%$ as summarised in Figure 8. Together with comparing results between two hospitals (axes labels) using the $y=x$ line, the plot can also assess ranking for each PPE. These results indicated that there's low supply of some types of the PPE in hospitals, which calls for sensitization of hospital administrators. Apart from PPE supply/availability, the level of PPE utilization was also a problem, whereby, gloves utilisation is over $80 \%$ in both hospitals, apron (Amana 58\%/Ligula 65\%), masks (Amana 50\%/Ligula 55\%) and all other PPE utilization level was below 50\%, which indicates a strong relationship between supply and utilisation. Compared with results in Figure 7, it is evident that for infection prevention of the highly perceived diseases, there should be higher supply and utilisation of masks than gloves and aprons, contrary to Figure 8.

\subsection{Knowledge and Skills of HWs on MWM}

The levels of knowledge and skills among HWs on MWM issues were studied in order to establish training needs and preparation of comprehensive training package. The areas studied include: knowledge and skills test, training need assessment and knowledge of HWs on administrative issues such as presence of MWM legislation, policy, manuals, guidelines, plans, presence of MWM team and clearly defined SOPs.

HWs were given multiple choice questions to choose by ticking the right answers, in order to test their knowledge and skills. The questions asked covered such areas like sharps waste management, medical waste segregation, nosocomial infection, HIV infection, management of expired drugs, MWM responsibilities, needle stick injuries, needle recapping, wastewater risks, management of patient human waste, HWs hand washing, disposal of glass ampoules, soft waste disposal, placenta disposal, types of medical waste and disposal of food remains. The mark for each respondent were aggregated and recorded and the results were as shown in Figure 9. It was revealed that, in Amana hospital, 61\% of HWs had low knowledge and 39\% had high knowledge levels, while at Ligula the results showed 57\% had low knowledge and $43 \%$ of HWs had high knowledge and skills on MWM. When results were integrated, it was observed in both hospitals that about $60 \%$ of HWs had low knowledge and skills in MWM which can be used as national averages.

\subsection{Training Needs Assessment}

In order to conduct training needs assessment, the MWM issues were grouped in following major topics, that is, administrative issues, hazards associated, PPE/infection prevention, collection storage and transportation, treatment and disposal of medical waste. In both hospitals, the respondents were asked to mark 5 for the topic with high training needs and down to 1 for the topic with least training needs. In order of priority, these ranking were 

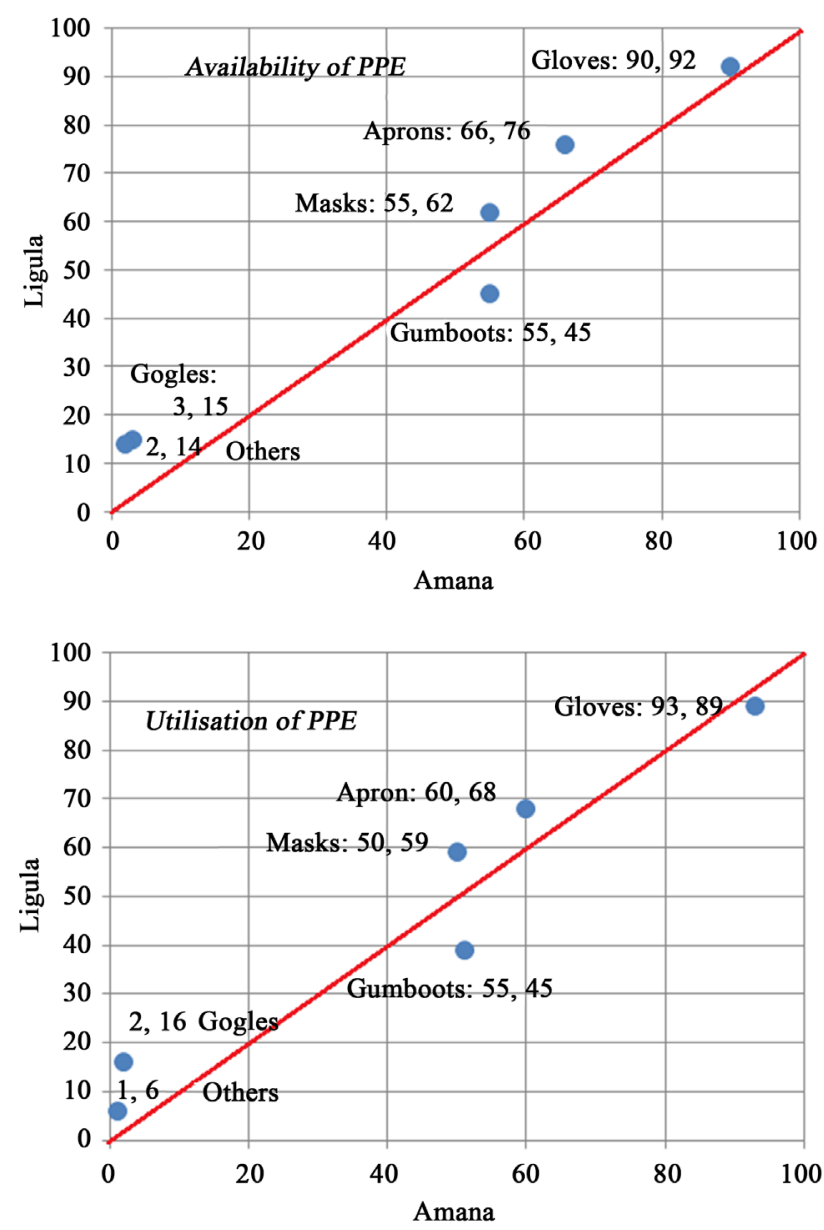

Figure 8. Availability and utilisation of personal protective equipment between Amana and Ligula hospitals.

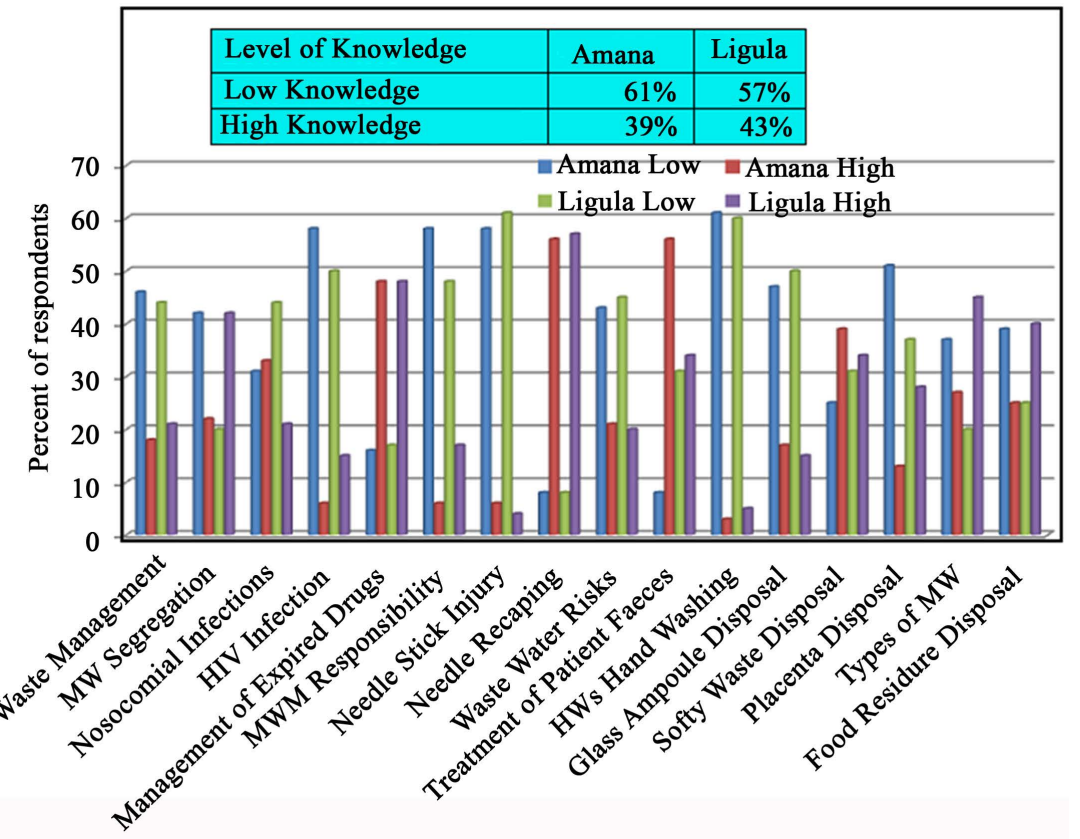

Figure 9. Summary of HWs knowledge and skill test results. 
aggregated at each topic and analysed. It was revealed that in both Amana and Ligula hospitals, the results were the same, that is, $27 \%$ needed training in hazards associated with MWM, 24\% in collection, storage and transportation, $22 \%$ in treatment/disposal and $14 \%$ in administrative issues.

\subsection{Knowledge of HWs on Administrative Issues}

Good and effective hospital administration is very important in MWM. The understanding of HWs in administrative issues associated with MWM was also assessed in this study. The areas studied included medical waste legislation, policy, manuals/guidelines, medical waste management planning, medical waste management team and presence of clearly defined SOPs on medical waste in these hospitals as shown in Figure 10.

When the results in Amana hospital were analysed it was revealed that, the level of HWs understanding on the existence of manuals and guidelines is only 36\% and in some important issues like presence of operational procedures and presence of legislation guiding MWM it was $0 \%$. When the same results were analysed at Ligula hospital it was observed that the level of HWs understanding the existence of manuals and guidelines was 31\% and for the presence of operational procedures it was $0 \%$.

It was observed that the existence of important administrative documents such as legislations, policies, manuals, plans and operational procedures in all hospitals is below 40\%. This indicates that HWs are operating on intuition, not guided by any management tool, which lead to poor MWM.

\subsection{General Discussion}

This paper gives an insight of perception of hospital managers (administrators or decision makers) and HWs (implementers) on MWM. Study done has established a baseline of information and statistics on perception of HWs on MWM from generation to final disposal. The perceptions of HWs on MWM have been properly analysed and recorded to give information that can form the basis for realistic planning, designing, budgeting and implementation of MWM, which is economical, effective and efficient.

Different perceptions on waste generation rate between administrators and implementers makes MWM (especially in the area of planning and resource allocation) to be difficult as administrators do not feel the exact burden of financial and human resources required for MWM, thus, giving less priority and leaving burden to the lower level implementers with limited resources. The data developed shows the magnitude of the problem and extent of the gap between HWs, based on which awareness and proper resource allocation can be improved.

Although the HWs' perception on medical waste segregation showed that most HWs understand the importance of segregation, the only major problem with segregation practices is on hospital administrators who provide limited and substandard waste collection facilities. The results showed also that only three categories of

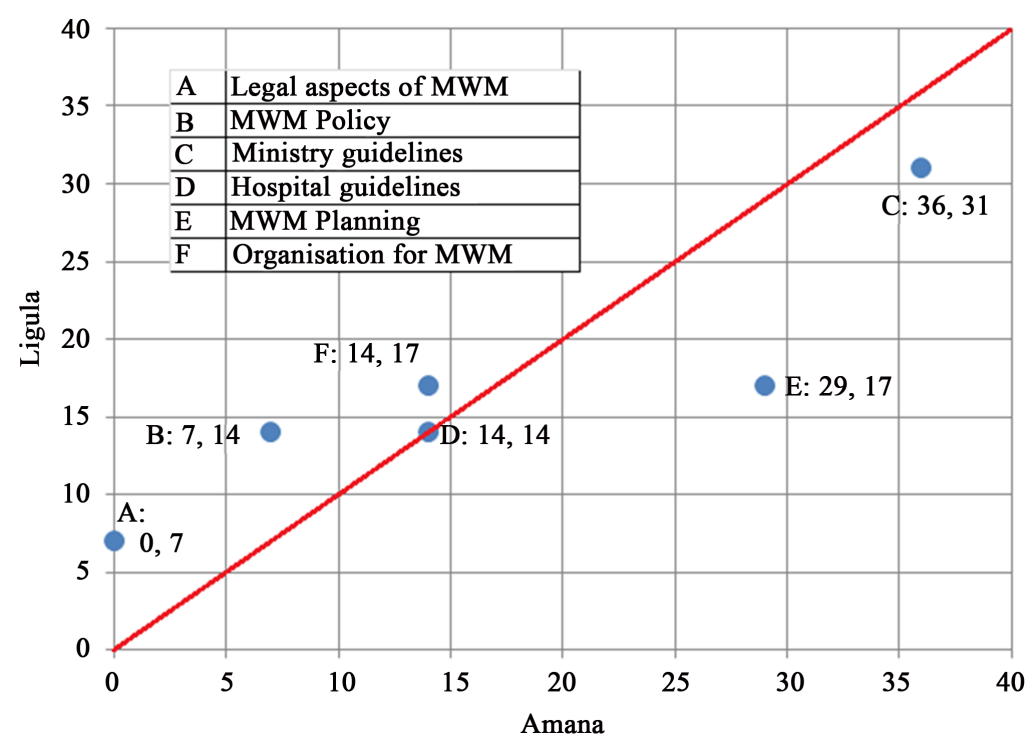

Figure 10. Knowledge of HWs on administrative issues. 
medical waste are being paid dual attention in Tanzanian hospitals, that is, sharps waste, pathological waste and infectious waste. Other wastes like radioactive, chemical, pharmaceutical, pressurized containers, etc., received little attention. The reason for critical attention on these three types lies on the fact that pathological and infectious wastes are aesthetic and raise alarm from community members when not well managed compared to other waste categories. This indicates that the hospital administrators deal with medical waste under pressure and not as part of their duties, necessitating sensitisation and training on proper planning.

The observation of not segregating all medical waste at source was attributed to less priority on medical waste handling especially on proper waste collection facilities by the hospital administration. The medical waste should remain segregated at generation point, during transportation and storage, during treatment until disposal. It is interesting to note that, other sections of Amana and Ligula hospitals were still using improvised containers, indicating sigs of compromised quality of services.

It was further revealed that HWs lack knowledge on segregation, they need special containers labelled from the factories, and some indicated segregation as a tedious job in their sections. Segregation of MWM is also hampered by the fact that the supply of medical waste collection facilities in hospitals is not smooth as most of containers are old and broken. This is still an indication that less priority is given to MWM by administrators accelerated by poor planning and limited fund allocation. The hospitals, however, have excellent medical waste collection efficiency. The medical waste collected twice a day includes pathological waste from labour and theatre rooms and infectious waste from isolation wards. The waste collected daily includes all other waste from different sections of the hospital other than safety boxes and packaging materials from pharmacy and stores, which are collected weekly.

The general cleanliness of the hospital environment and operation of incinerator in hospitals is done by auxiliary nurses, who do not have enough skills on MWM as they have been observed wearing soft gloves and handling waste including sharps, picking waste and loading into the incineration chamber with bare hands.

An intensive training on medical waste collection, storage and transportation is required. Moreover, provision of standard waste collection facilities, provision of special carts designed for medical waste transportation inside hospitals and construction of special medical waste collection bays to store waste collected from various hospital sections, waiting for onsite treatment or to be transported outside for final disposal, is of vital importance.

Although Amana hospital has shown improvements in MWM, its waste transported offsite cause pollution to the environment especially to soil and water at Pugu dumpsite which is managed by municipal council authorities in Dar es Salaam. The Council authority is advised to treat medical waste separately from other solid waste and other technologies such as large scale incineration before land filling.

The different views and perceptions observed between administrators and implementers makes MWM especially in the area of planning and resource allocation to be difficult as administrators (supervisors and doctors) do not feel the exact burden of work, which makes them give less priority while the whole burden is being left to the lower level implementers with limited resources. Container coding and labelling is very important in MWM. The collection centres included sluice rooms to store pathological and infectious waste while other wastes are stored at the waste collection zone in Amana and refuse bay at Ligula hospital.

The management of medical waste was formally the sole duty of the hospital itself, but nowadays, some hospitals has gone a step ahead and are now privatizing the service, as observed at Amana hospital. This can be a problem if those workers are not trained. These hospitals are not properly managing their waste, practices of which require improvements. The situation is caused by poor MWM infrastructure, shortcomings in management teams, low knowledge among HWs on appropriate medical waste treatment/disposal technologies as well as on administrative issues. Perceptions of HWs on MWM are a key towards understanding and solving MWM problems in hospitals.

\section{Conclusions}

Based on the above findings, it can be concluded that:

1) The perceived total waste generation rates are lower than the actual measured medical waste generation in both hospitals. Moreover, administrators perceive lower rates than implementers of MWM, leading to poor resource allocation.

2) The results indicated three categories of medical waste which are being given due attention and are well segregated in Tanzanian hospitals, that is, sharps waste, pathological and infectious waste. Other wastes like 
radioactive, chemical, pharmaceutical, pressurized containers and others receive very little attention. Container colour coding and labelling is almost negligible, while improvised containers are still in use in Tanzanian hospitals (43\% and 86\% at Amana and Ligula hospitals, respectively).

3) Medical waste is transported within hospitals manually (40\% and 33\% for Amana and Ligula hospitals, respectively). Wheelbarrows are used to a small extent and there are no special carts designed for the purpose of medical waste transportation in the hospitals. A problem of poor waste storage facilities is critical in Tanzanian hospitals, which allows mixing of waste during storage by animals and scavengers, posing a health risk for incinerator operators and off-site transporters.

4) The prominent medical waste treatment technologies in Tanzanian hospitals are on-site medium temperature incinerators and off-site transportation where the waste is mainly dumped or buried. The hospitals are currently utilizing public-private partnership schemes for MWM in only one aspect of off-site transportation.

5) The study has revealed that three main problems hindering MWM in Tanzanian hospitals and which require high attention include: weaknesses in hospital management, lack of MWM facilities or infrastructure, and lack of skills and knowledge on MWM among HWs. Knowledge and skills among HWs on health hazards associated with poor MWM were observed to be low in both hospitals (with exception of cholera, HIV and typhoid). Few PPE types are supplied and used in the hospitals, that is, gloves, masks and aprons, such that only few diseases can be prevented. There is also low knowledge among HWs on administrative issues related to MWM in Tanzanian hospitals, which calls for training for all HWs.

\section{References}

[1] Sharma, S. (2010) Awareness about Bio-Medical Waste Management among Health Care Personnel of Some Important Medical Centers in Agra. International Journal of Environmental Science and Development, 1, 251-255. http://dx.doi.org/10.7763/IJESD.2010.V1.48

[2] Lakshmi, B.S. and Kumar, P. (2012) Awareness about Bio-Medical Waste Management among Healthcare Personnel of some Important Medical Centers in Agra. International Journal of Engineering Research and Technology, 1, 1-5.

[3] Vishal, B., Swarn, L., Mahesh, M., Arvind, A., Sanjay, A. and Uma, S. (2012) Knowledge Assessment of Hospital Staff Regarding Biomedical Waste Management in A Tertiary Care Hospital. National Journal of Community Medicine, 3, 197-200.

[4] Mesfin, K.D., Kassahun, A.G., Andamlak, G.A. and Zemedu, M.T. (2013) Assessment of the Health Care Waste Generation Rates and Its Management System in Hospitals of Addis Ababa, Ethiopia. BioMedical Central Public Health, 13, 1-9.

[5] Hossain, M.S., Santhanam, A., Nik Norulaini, N.A. and Omar, A.K. (2011) Clinical Solid Waste Management Practices and its Impact on Human Health and Environment-A Review. Waste Management, 31, 754-766. http://dx.doi.org/10.1016/j.wasman.2010.11.008

[6] Idowu, I., Alo, B., Atherton, W. and Al Khaddar, R. (2013) Profile of Medical Waste Management in two Healthcare Facilities in Lagos, Nigeria: A Case Study. Waste Management \& Research, 31, 494-501. http://dx.doi.org/10.1177/0734242X13479429

[7] Yenesew, M.A., Moges, H.G. and Woldeyohannes, S.M. (2012) A Cross Sectional Study on Factors Associated with Risk Perception of Healthcare Workers toward Healthcare Waste Management in Health Care Facilities of Gondar Town, Northwest Ethiopia. International Journal of Infection Control, 8, 1-9. http://dx.doi.org/10.3396/ijic.v8i3.024.12

[8] Mathur, V., Dwivedi, S., Hassan, M.A. and Misra, R.P. (2011) Knowledge, Attitude, and Practices about Biomedical Waste Management among Healthcare Personnel: A Cross-Sectional Study. Indian Journal of Community Medicine, 36, No. 2, 143-145. http://dx.doi.org/10.4103/0970-0218.84135

[9] Ozder, A., Teker, B., Eker, H.H., Altindis, S., Kocaakman, M. and Karabay, O. (2013) Medical Waste Management Training for Healthcare Managers-A Necessity? Journal of Environmental Health Science and Engineering, 11, 1-8. http://dx.doi.org/10.1186/2052-336x-11-20

[10] Manyele, S.V. and Kagonji, I.S. (2012) Analysis of Medical Waste Incinerator Performance Based on Fuel Consumption and Incineration Cycle Times. Engineering, 4, 625-635. http://dx.doi.org/10.4236/eng.2012.410080

[11] Matee, V.E. and Manyele, S.V. (2015) Analysis of Temperature Profiles and Cycle Time in a Large-Scale Medical Waste Incinerator. Engineering, 7, 717-732. http://dx.doi.org/10.4236/eng.2015.710063

[12] Matee, V.E. and Manyele, S.V. (2016) Assessment of Sharps Waste Management Practices in a Referral Hospital. African Journal of Environmental Science and Technology (AJEST), 10, 86-95. http://dx.doi.org/10.5897/AJEST2015.1939 
[13] Mato, R.R.A.M. Kassenga, G.R. (1997) Problems of Management of Medical Solid Wastes in Dar es Salaam and Their Remedial Measures. Resource Conservation and Recycling, 21, 1-16. http://dx.doi.org/10.1016/S0921-3449(97)00010-4

[14] Hamoda, H.M., Tomi, H.N. and Bahman, Q.Y. (2005) Variations in Hospital Waste Quantities and Generation Rates. Journal of Environmental Science and Health, 40, 467-476. http://dx.doi.org/10.1081/ESE-200045650

[15] Engdaw, D., Sulaiman, H. and Leta, S. (2009) Determining the Generation Rate and Composition of Solid Health Care Waste at Gondar University Hospital. Ethiopian Journal of Health and Biomedical Sciences, 1, 17-21.

[16] Kagonji, I.S. and Manyele, S.V. (2011) Analysis of the Measured Medical Waste Generation at Amana and Ligula Hospitals Using Statistical Methods. African Journal of Environmental Science and Technology (AJEST), 5, 815-833.

[17] Patwary, M.A., O’Hare, W.T., Street, G., Maudood Elahi, K., Hossain, S.S. and Sarker, M.H. (2009) Quantitative Assessment of Medical Waste Generation in the Capital City of Bangladesh. Waste Management \& Research, 29, 23922397. http://dx.doi.org/10.1016/j.wasman.2009.03.021

[18] Haylamicheal, I.D., Dalvie, M.A., Yirsaw, B.D. and Zegeye, H.A. (2011) Assessing the Management of Healthcare Waste in Hawassa City, Ethiopia. Waste Management \& Research, 29, 854-862. http://dx.doi.org/10.1177/0734242X10379496

[19] MOHSW (Ministry of Health and Social Welfare) (2006) National Policy Guidelines on Healthcare Waste Management. Dar es Salaam, Tanzania.

[20] Kaseva, M.E. and Mato, R.R.A.M. (1999) Critical Review of Industrial and Medical Waste Practices in Dar es Salaam City. Resource Conservation and Recycling, 25, 271-287. http://dx.doi.org/10.1016/S0921-3449(98)00068-8

[21] Bdour, A., Altrabsheh, B., Hadadin, N. and Al-Shareif, M. (2007) Assessment of Medical Wastes Management Practice: A Case Study of the Northern Part of Jordan. Waste Management, 27, 746-759. http://dx.doi.org/10.1016/j.wasman.2006.03.004

[22] Nemathaga, F., Maringa, S. and Chimuka, L. (2008) Hospital Solid Waste Management Practices in Limpopo Province, South Africa: A Case Study of Two Hospitals. Waste Management, 28, 1236-1245. http://dx.doi.org/10.1016/j.wasman.2007.03.033

[23] Sawalem, M., Selic, E. and Herbell, J.D. (2009) Hospital Waste Management in Libya: A Case Study. Waste Management, 29, 1370-1375. http://dx.doi.org/10.1016/j.wasman.2008.08.028

[24] US DOE (US Department of Energy) (1996) Handbook for Occupational Health and Safety during Hazardous Waste Activities. Office of Environmental Management, US Department of Energy.

[25] Suwarna, M. and Ramesh, G. (2012) Study about Awareness and Practices about Healthcare Wastes Management among Hospital Staff in a Medical College Hospital, Bangalore. International Journal of Basic Medical Sciences, 3, $7-11$.

\section{Scientific Research Publishing}

\section{Submit or recommend next manuscript to SCIRP and we will provide best service for you:}

Accepting pre-submission inquiries through Email, Facebook, LinkedIn, Twitter, etc.

A wide selection of journals (inclusive of 9 subjects, more than 200 journals)

Providing 24-hour high-quality service

User-friendly online submission system

Fair and swift peer-review system

Efficient typesetting and proofreading procedure

Display of the result of downloads and visits, as well as the number of cited articles

Maximum dissemination of your research work

Submit your manuscript at: http://papersubmission.scirp.org/ 